\title{
The SAC 3.0 Android-Based Application as A Learning Media in Teaching Basic BIPA
}

\author{
Dewi Kusumaningsih ${ }^{1}$, Nur Rochman Fatoni ${ }^{2}$ \\ ${ }^{1}$ Universitas Veteran Bangun Nusantara, Indonesia, ${ }^{2}$ Universitas Sebelas Maret, Indonesia, \\ 1 dewikusumaningsih71@univetbantara.ac.id \\ nrf.fatoni@student.uns.ac.id
}

\begin{abstract}
The Indonesian Language for Foreign Speakers (Bahasa Indonesia Untuk Penutur Asing - BIPA) requires appropriate Android-based learning media produced by using the Smart Application Creator (SAC) 3.0. This investigation highlighted the learning innovation by utilizing the innovation of Android-based learning media to facilitate the basic BIPA learning activities. The SAC 3.0 as a learning media creator for BIPA was firstly developed by the Computer Technology Training and Development Center (Computer Technology Training and Development Center - BPMTK) in Central Java Province. This study shared a number of procedures in producing the SAC 3.0-based learning media for BIPA, in addition to its advantages and drawbacks. This research targeted the presentation of basic learning materials for BIPA related to the introduction of transportations using Indonesian Language through the Android application.
\end{abstract}

Keywords: BIPA learning media, Android-based, SAC 2.0.

\section{PENDAHULUAN}

Bahasa dalam pembelajarannya tidak bisa dilepaskan dari aspek budaya dan aspek komunikasi [1]. Hal ini juga menjadi pertimbangan dalam pembelajaran BIPA (Bahasa Indonesia untuk Penutur Asing). Para penutur asing yang notabene jelas memiliki latar belakang budaya dan etika atau cara berkomunikasi yang berbeda memerlukan bantuan dalam mengintegrasikan dirinya pada bahasa Indonesia dan budayanya. Aspek budaya bisa didapatkan mereka dari pergaulan dengan komunitas lokal. Sedangan dalam aspek komunikasi, diperlukan sebuah alat bantu pada masing-masing individu yang bersifat independent untuk mereka belajar sebuah bahasa yang mencakup penggunaan kata, frasa, klausa, dan kalimat.

Media belajar yang bersifat independent yang memiliki ketertarikan tinggi pada generasi zaman ini bisa menjadi alternatif pembelajaran bahasa. Contoh kecil yang menginspirasi hal itu adalah anak yang sering menggunakan aplikasi game pada telepon seluler dengan bahasa pengantar bahasa Inggris akan lebih banyak memiliki kosakata bahasa Inggris dan juga paham konteks kosakata tersebut digunakan. Hal ini yang menjadi ide bahwa penggunaan sebuah media belajaran yang terintegrasi pada telepon seluler mereka khususnya pada sistem android akan membantu para penutur asing belajar bahasa Indonesia. Penggunaan media pembelajaran kekinian yang menggunakan aplikasi berbasis android bisa menjadi alternatif yang tepat karena di dalamnya akan terdapat poin poin sebagai target pembelajaran yang akan mudah dan menyenangkan digunakan oleh penutur asing. Menurut [2] setiap pembelajaran, selain mempunyai tujuan, tentunya memiliki prospek pembelajaran yang mana harus diperhatikan 
seorang pengajar. Prospek adalah jarak antara tujuan dan treatment untuk mencapainya. Salah satu faktor untuk melihat prospek ini adalah penggunaan media pembelajaran.

Pembelajaran bahasa tidak bisa dilepaskan dari pemahaman konsep gramatika atau kontekstual penggunaan suatu bahasa. Dalam pembelajaran BIPA, para pembelajar jelas masih terpengaruh oleh konsep bahasa ibu dari negara mereka [3]. Dalam hal ini perlu adanya media untuk menunjang basic pemahaman bahasa para pembelajar BIPA dengan cara yang lebih internalized pada diri pembelajar. Maksud dari internalized disini adalah bahwa cara belajar bahasa tersebut harus melingkupi keseharian mereka dan bisa mereka akses sehari-hari.

Smart Aplication Creator (SAC) 3.0 adalah suatu aplikasi yang dikembangkan oleh Balai Pelatihan dan Pengembangan Teknologi Komputer (BMPTK) Semarang, Jawa Tengah. Aplikasi ini mampu dipergunakan untuk media pembelajaran berbagai ilmu pengetahuan mulai tingkat dasar sampai tingkat lanjut. Kali ini SAC 3.0 dipakai sebagai salah satu media pembelajaran bagi BIPA dasar. Materi dasar pengenalan transportasi dibuat sebagai konten dalam SAC 3.0 ini. Di dalamnya terdapat gambar-gambar alat transportasi yang dipergunakan di Indonesia berupa gambar, tulisan, dan suara.

Telah banyak peneliti yang concern terhadap permasalahan yang terjadi pada pembelajaran BIPA. Penelitian [4] berusaha memaparkan salah satu kesalahan siswa BIPA dalam belajar bahasa Indonesia. Peneliti dalam hal ini fokus pada kesalahan yang dilakukan yakni ketidaklaziman kolokasi pada pembelajar BIPA. Penelitian pengembangan media pembelajaran untuk BIPA sesungguhnya luas. Penelitian dari [5] bisa menjadi salah satu contoh, akan tetapi fokus media pembelajarannya adalah dengan integrasi unsur budaya.

Penelitian terkait media pembelajaran berbasis android juga telah ada. Hal ini membuktikan besarnya kemungkinan penggunaan sistem aplikasi android akan berhasil pula dalam pembelajaran bahasa. Salah satunya yaitu peneliti dari semarang yang menggunakan media berbasis android dalam membantu pengembangan pembelajaran dan keefektifan selama proses pembelajaran. Dalam penelitian tersebut, peneliti menggunakan alat (device) computer. Dari penelitian tersebut didapatkan bahwa suatu media computer yang berbasis aplikasi di andorid mudah digunakan dan mendukung sutu pembelajaran yang terstruktur bagi siswa, khususnya jurusan matematika [6]. Selain itu, peggunaan media berbasis android juga diterapkan pada guru untuk mengajar siswa di STMIK AKBA. Hasil penelitian tersebut membuktikan bahwa dengan media berbasis android mampu meningkatkan pencapaian prestasi siswa [7].

\section{METODE PENELITIAN}

Rancangan pembuatan aplikasi ini menggunakan alur pengembangan multimedia yang diberikan oleh BPMTK Jawa Tengah dari konsep yang dikemukakan oleh Luther [8]. Alur pengembangan multimedia ini adalah langkah-langkah urutan pembuatan media secara berurutan. Urutan tersebut adalah Concept, Design, Material Collecting, Assembly, Testing, dan Distribution atau padanannya adalah konsep, desain, pengumpulan materi, pembuatan program, pengujian program, dan pendistribusian program. 


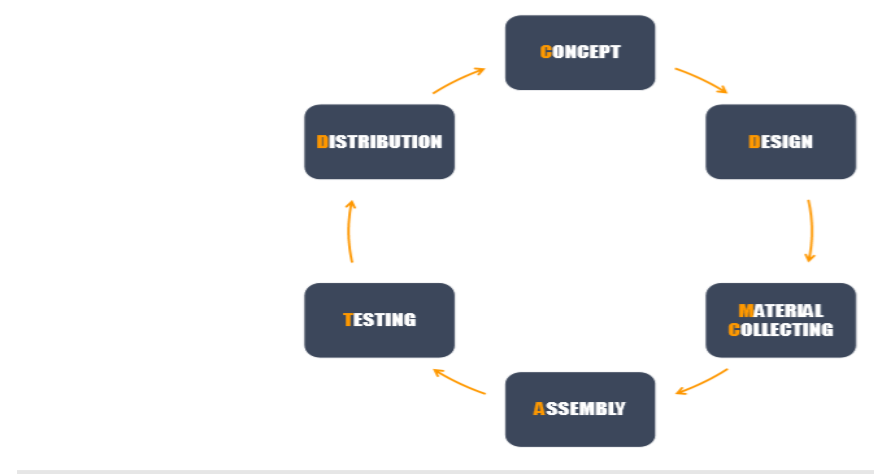

Gambar 1. Alur Pengembangan Multimedia

Secara lengkap uraian dari alur pengembangan multimedia yang dipergunakan dalam SAC 3.0 adalah sebagai berikut:

a. Concept

Konsep dibuat di awal tahapan karena dipakai sebagai panduan keseluruhan program meuju ketercapaian tujuan. Konsep awal dibuat berisi tujuan media pembelajaran ini ditujukan pada pembelajar BIPA level 1 yaitu BIPA dasar. Kesesuaian semua sumber materi BIPA dasar dicari dari sumber belajar di laman Badan Bahasa bagian BIPA. Konsep lanjutan yang dibuat adalah pembuatan naskah rancangan media yang akan dibuat diurutkan sesuai tampilan dari awal aplikasi sampai bagian akhir tampilan layer di android. Seluruh naskah ini dirangkum dalam storyboard. Storyboard sebagai tempat rancangan urutan tampilan yang akan dibuat dalam aplikasi di android. Berikut ini tampilan storyboard yang sudah dibuat:

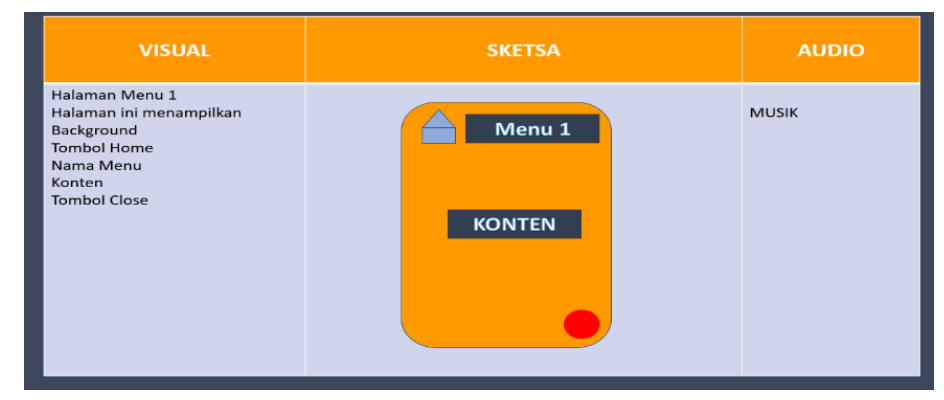

Gambar 2. Tampilan rancangan Storyboard

\section{b. Design}

Perancangan media yang dilakukan dengan langkah step by step dengan 5 bagian keseluruhan tampilan dan isi yang akan dibuat meliputi 1.Start page, 2. Opening, 3. Home, 4. Konten, dan 5. Developer. Semua bagian tersebut mempunyai isi yang dirancang dalam pembuatan media secara terintegrasi. 


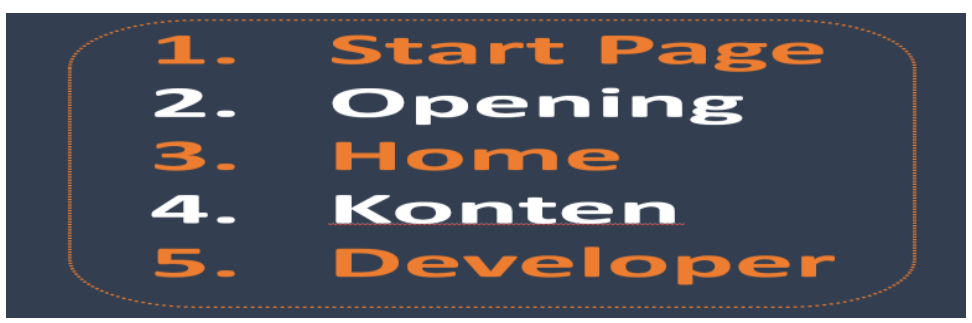

Gambar 3. Urutan Design Media SAC 3.0

\section{c. Material Collecting}

Tahap ini dilakukan pengumpulan bahan yang akan dipakai sebagai tampilan dari perangkat android. Bahan-bahan tersebut antara lain video, audio, teks, foto, gambar, animasi, dll.

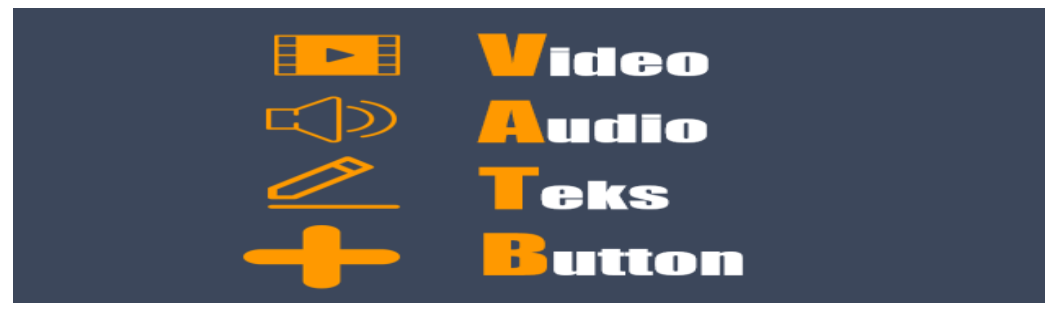

Gambar 4. Koleksi Aset

\section{d. Assembly}

Tahap assembly dilakukan penyusunan dan pembuatan semua asSeet yang sudah dikoleksi yaitu objek atau bahan multimedia. Pembuatan aplikasi berdasarkan rancangan story board, bagan alur, dan navigasi yang sudah direncanakan.

e. Testing:

Tahap ini dilakukan penggunaan aplikasi untuk dilihat apakah sudah sesuai dengan kebutuhan. Di tahap ini dilakukan pengujian aplikasi oleh pengajar BIPA maupun perancang teknologi pendidikan.

\section{f. Distribution}

Tahap akhir adalah pendistribusian aplikasi yang disimpan dalam sebuah media kepada pengguna. Pendistrubusian aplikasi ini dibantu oleh aplikasi lain yang bisa diinstal dalam media android.

\section{HASIL DAN PEMBAHASAN}

\subsection{Media Berbasis Android}

Android adalah sistem operasi terbuka, dikembangkan linux, yang biasa dipergunakan pada telepon genggam terkiri yang mencakup pula sistem-sistem aplikasi, dikembangkan oleh java, yang memiliki bebagai macam fungsi [9]. Penggunaan aplikasi android untuk pembelajaran telah dicoba dalam bidang pendidikan yang lain. Maka bukanlah mustahil dalam pengajaran BIPA menggunakan media pembelajaran dengan aplikasi belajar bahasa dalam sistem operasi android. 
Pemilihan media pembelajaran harus memperhatikan keadaan-keadaan realita yang terjadi pada sistem pembelajaran. Media pembelajaran telah banyak dilakukan oleh guru untuk menunjang proses belajar mengajar. Penggunaan media berbasis android ini juga membuka peluang untuk siswa maupun guru dalam mengeksplore ilmu pengetahuan, selain itu keberadaan android ini telah dekat dengan keseharain siswa [10].

\subsection{Perancangan dan Implementasi}

Seperti telah dituliskan di atas tentang alur pengembangan multimedia, di bawah ini hasil tampilan dari aplikasi SAC 3.0 yang memuat materi kosakata transportasi dalam android.

a. Halaman Loading dan cover aplikasi

Halaman loading dan cover aplikasi merupakan halaman pembuka dari media SAC 3.0. sebagai Media Pembelajaran BIPA Dasar. Di dalam tampilan awal, cover warna biru mendominasi layar. Tertulis judul Alat Transportasi dengan tambahan ilustrasi gambar berupa serangkaian benda yang biasa dipakai untuk bepergian yaitu jam tangan, topi, telepon genggam, pesawat, paspor, dan sepatu. Setelah masuk halaman loading ini untuk memasuki halaman selanjutnya maka klik tulisan MASUK yang terdapat pada pojok kiri bawah halaman yang dapat dilihat pada gambar sebagai berikut:

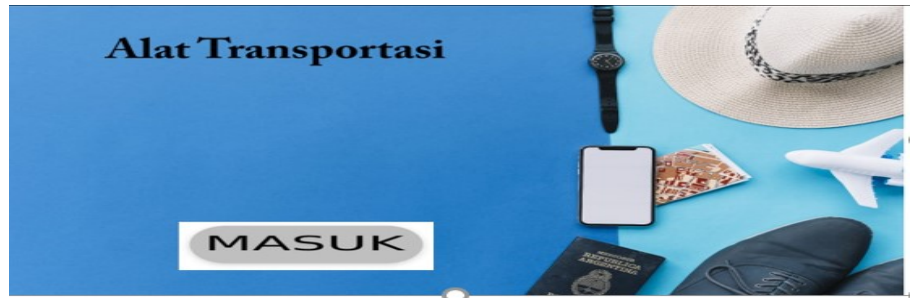

Gambar 5. Halaman Loading dari Aplikasi SAC 3

b. Halaman Menu Utama

Setelah kata MASUK dipencet, maka tampilan layar berisi video audio bergambar yaitu materi mengenai transportasi yang ada di Indonesia. Halaman ini merupakan materi dasar yang dapat dipelajari di BIPA. Materi audio yaitu lagu yang berjudul Anak Kambing. Pemutaran video bergambar disertai keterangan nama dari gambar yang tertera di video dirangkum secara menarik sehingga mudah untuk diingat dan dipelajari.

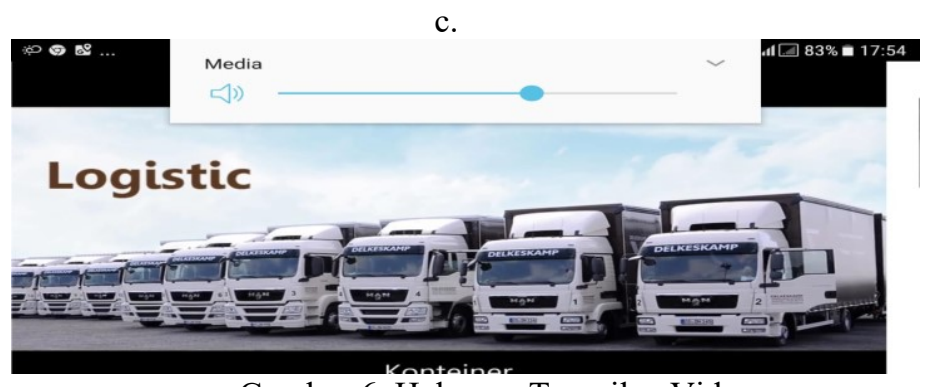

Gambar 6. Halaman Tampilan Video

c. Halaman materi utama yang merupakan halaman yang mengambarkan tampilan awal saat memasuki media pembelajaran BIPA berbasis android. Pada halaman ini berisi 
peta konsep dibuatnya aplikasi SAC 3.0. media pembelajaran BIPA dasar. Awalan ini memberi petunjuk materi yang akan diputar dalam bentuk gambar moda transpotasi di Indonesia disertai teks dan audionya. Lihat gambar di bawah ini:

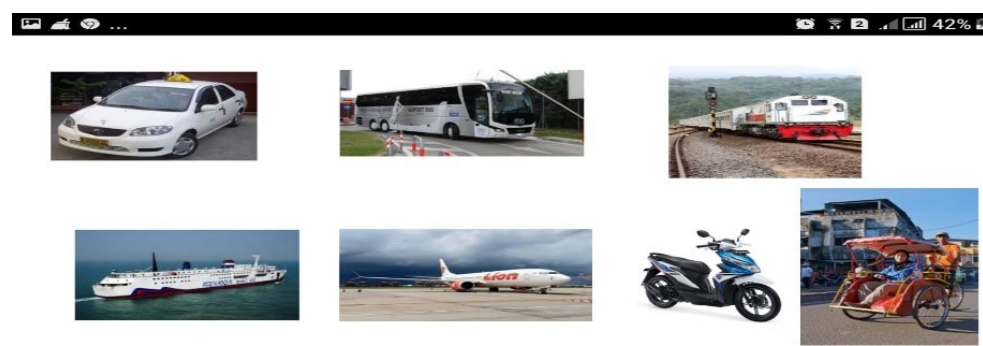

\subsection{Diskusi}

Gambar 7. Halaman Materi Utama dari Aplikassi SAC 3.0

Hasil pembuatan media pembelajaran BIPA dengan aplikasi SAC 3.0 ini merupakan salah satu usaha pengembangan multimedia dalam pembelajaran. Rancangan ini sepenuhnya masih dalam tahap awal, sehingga masil terlihat sangat sederhana. Meskipun demikian, inovasi media pembelajaran berbasis android ini layak untuk dipertimbangkan sebagai salah satu unggulan aplikasi dalam pembelajaran ilmu pengetahuan pada umumnya dan BIPA khususnya. Meskipun sederhana, hasil inovasi ini ternyata juga pernah dilakukan oleh [11], [12] dengan objek sebuah aplikasi media pembelajaran berbasis Teknologi Informasi dan Komunikasi (TIK) dengan animasi berupa tampilan dari konten dan diiringi dengan latar suara. Variasi pembuatan media yang sudah dilakukan oleh penulis tersebut menggunakan model research and Development $(R$ and $D$ ) dengan mengunakan 4 tahap yaitu pendefenisian, perancangan, pengembangan, dan penyebaran. Penelitian bagaikanapun bentuknya bahwa inovasi pembelajaran dengan menggunakan media khususnya multimedia berbasis computer maupun aplikasi sudah layak dan diharuskan penggunaannya mengingat perkembangan ilmu pengetahuan dan teknologi yang sangat pesat yang sudah mencapai era 5.0 [13]

\section{SIMPULAN}

Secara umum, sebuah media pembelajaran harus memperhatikan beberapa pertimbangan. Dari pertimbangan-pertimbangan yang ada, disertai dengan perkembangan zaman, membuka peluang adanya inovasi pada kreasi media pembelajaran yang diigunakan untuk belajar Bahasa Indonesia khususnya untuk para penutur asing. Dari penelitian dan pengembangan aplikasi berbasis android untuk pembelajaran BIPA ini ada warna baru dengan tampilan materi di telepon gengam yang praktis dan dinamis.

\section{REFERENCES}

[1] K. Saddhono, "Integrating Culture in Indonesian Language Learning for Foreign Speakers at Indonesian Universities,” J. Lang. Lit., vol. 6, no. 2, pp. 273-276, 2015.

[2] I. Suyitno, Y. Pratiwi, Roekhan, and Martutik, "How Prior Knowledge, Prospect, and Learning Behaviour Determine Learning Outcomes of BIPA Students?," Cakrawala Pendidik., vol. 38, no. 3, pp. 499-510, 2019.

[3] S. A. Ningsih and L. Muliastuti, "Developing Syllabus and Reading Teaching Materials for BIPA A1 Based on Deductive Approach," AKSIS J. Pendidik. Bhs. dan Sastra 
Indones., vol. 3, no. 1, pp. 1-11, 2019.

[4] M. Said, "Ketidaklaziman Kolokasi Pembelajar Bipa Dan Implikasinya Terhadap Pembelajaran Bahasa," J. Cakrawala Pendidik., vol. 2, no. 2, pp. 204-213, 2010.

[5] A. M. N. Setiawan, Andayani, and K. Saddhono, "The Use of Writing Learning Media for Bipa Students To Understand Local Culture," Komposisi J. Pendidik. Bahasa, Sastra, dan Seni, vol. 18, no. 1, pp. 66-79, 2017.

[6] P. Hendikawati, M. Z. Zahid, and R. Arifudin, "Android-Based Computer Assisted Instruction Development as a Learning Resource for Supporting Self-Regulated Learning," Int. J. Instr., vol. 12, no. 3, pp. 389-404, 2019.

[7] A. Iskandar, D. Utami Sutiksno, N. Kurniasih, D. Palimbong, and A. Paulus Saleky, "Designing Android-based learning media and assessment in improving students achievement," J. Phys. Conf. Ser., vol. 1175, no. 012231, 2019.

[8] A. Purwanto, "Multimedia Pembelajaran Bahasa Indonesia untuk Mahasiswa Berbasis Animasi,” J. Sist. dan Inform., vol. 4, no. 1, pp. 51-58, 2016.

[9] J. Liu and J. Yu, "Research on Development of Android Applications," in 2011 Fourth International Conference on Intelligent Networks and Intelligent Systems Research, 2011, pp. 69-72.

[10] Qumillaila, B. H. Susanti, and Zulfiani, "Developing Android version of Augmented Reality As A Learning Media of Human Excrement System," Cakrawala Pendidik., vol. Februari, no. 1, pp. 57-69, 2017.

[11] A. Purwanto, "Multimedia Pembelajaran Bahasa Indonesia untuk Mahasiswa Berbasis Animasi," J. Sist. dan Inform., vol. 11, no. 1, pp. 6-7.

[12] J. Veri and E. Prasetia, "Perancangan Dan Pembuatan Aplikasi Media Pembelajaran Perakitan Komputer Berbasis Android," Pendidik. dan Teknol. Inf., vol. 4, no. 2, pp. 219-229, 2017.

[13] K. Saddhono, A. Hasibuan, and M. I. Bakhtiar, "Facebook as A Learning Media in TISOL (Teaching Indonesian to Speakers of Other Languages) Learning to Support The Independency of Foreign Students in Indonesia," in Journal of Physics: Conference Series, 2019, vol. 1254, no. 1, p. 12061. 